\title{
A Dominant Negative Egr Inhibitor Blocks Nerve Growth Factor-Induced Neurite Outgrowth by Suppressing c-Jun Activation: Role of an Egr/c-Jun Complex
}

\author{
Yechiel Levkovitz and Jay M. Baraban \\ Departments of Neuroscience and Psychiatry and Behavioral Sciences, Johns Hopkins University School of Medicine, \\ Baltimore, Maryland 21205
}

\begin{abstract}
Members of the Egr family of transcription factors are rapidly and robustly induced by neurotransmitters and neurotrophins and have been implicated in mediating enduring changes in neuronal function elicited by these stimuli. Because we have found in previous studies that a dominant negative inhibitor of Egr action, the Egr zinc finger domain (ZnEgr), blocks NGFinduced neurite outgrowth in PC12 cells, we have used this preparation to help identify the downstream targets of Egr proteins involved in plasticity. Our investigation into the mechanism of action of ZnEgr indicates that it blocks NGF-induced neurite outgrowth by suppressing activation of C-Jun, a critical step in the signaling pathway mediating this response. Although we had assumed that ZnEgr exerts its effects by binding to the Egr response element (ERE) and thereby blocking target
\end{abstract}

Recent studies have provided compelling evidence that the Egr family of transcription regulatory factors plays a critical role in mediating enduring forms of neuronal plasticity (O'Donovan et al., 1999; Wei et al., 2000; Jones et al., 2001). Accordingly, there has been intense interest in identifying the downstream targets of Egr proteins that mediate its role in the plasticity process. Because several studies indicate that Egr proteins play an essential role in mediating neurite outgrowth elicited by NGF in PC12 cells (Qu et al., 1998; Harada et al., 2001; Levkovitz and Baraban, 2001), this in vitro paradigm provides a convenient model system for investigating how Egr proteins contribute to long-term changes induced by cellular stimulation.

Two members of the Egr family, Egr1 and Egr4, are strongly induced as part of the immediate early gene response elicited by NGF in PC12 cells (Milbrandt, 1987; Sukhatme et al., 1988; Crosby et al., 1991). To examine the role of the Egr family in NGF signaling, we have used a dominant negative strategy based on the domain structure of Egr family members (Levkovitz et al., 2001). All four Egr family members share a highly conserved zinc finger DNA-binding domain (ZnEgr), which mediates their interaction with a consensus DNA-binding site, referred to as the Egr response element (ERE; Christy and Nathans, 1989; Gashler and Sukhatme, 1995; Swirnoff and Milbrandt, 1995). We found that

Received Nov. 20, 2001; revised Jan. 24, 2002; accepted Feb. 22, 2002.

This work was supported by grants from the National Institute on Drug Abuse and the National Alliance for Research on Schizophrenia and Depression. We thank D. Ginty and B. Ye for helpful discussions.

Correspondence should be addressed to Dr. Jay M. Baraban, Department of Neuroscience, Johns Hopkins University School of Medicine, 725 North Wolfe Street, Baltimore, MD 21205. E-mail: jbaraban@jhmi.edu.

Copyright (C) 2002 Society for Neuroscience $0270-6474 / 02 / 223845-10 \$ 15.00 / 0$ gene regulation by Egr proteins, this classical mode of action appears to be too slow to mediate the effects of Egr proteins on c-Jun activation. In evaluating alternative ERE-independent mechanisms of Egr (and ZnEgr) action, we found that Egr1 and C-Jun coprecipitate and that ZnEgr disrupts formation of the Egr1/c-Jun complex. Furthermore, mutations of ZnEgr that greatly impair or abolish its ability to bind to the ERE do not block its ability to suppress C-Jun activation or neurite outgrowth induced by NGF. Accordingly, our studies indicate that Egr and ZnEgr proteins regulate c-Jun activation via a novel mechanism, protein-protein interaction with c-Jun, rather than via their classical mode of action, binding to the ERE.

Key words: ERK; zif268; NGF-IA; Egr1; Egr response element; $A P-1$; zinc finger

this domain, which blocks the ability of Egr family members to stimulate ERE-mediated transcription, suppresses the ability of NGF to elicit neurite outgrowth in PC12 cells. Thus, these results indicate that one or both members of the Egr family induced by NGF are essential for mediating this response to NGF. However, they do not shed light on what role they play in this process. To address this issue, we have, in this study, examined how dominant negative Egr constructs affect the signaling pathway linking NGF receptor activation to neurite outgrowth.

It is well established that NGF-induced neurite outgrowth is mediated by activation of the ras/mitogen-activated protein kinase-extracellular signal-regulated kinase kinase (MEK)/extracellular signal-regulated kinase (ERK) cascade (Cowley et al., 1994; Pang et al., 1995; Segal and Greenberg, 1996). Furthermore, recent studies have identified c-Jun activation, mediated by phosphorylation of its N-terminal activation domain (Pulverer et al., 1991; Smeal et al., 1991; Papavassiliou et al., 1995), as a key downstream target of this pathway, linking it to neurite outgrowth (Leppa et al., 1998). Although it has been generally assumed that phosphorylation of the c-Jun $\mathrm{N}$ terminus is mediated by the c-Jun N-terminal kinase (JNK) family of kinases, rather than ERK family members (Derijard et al., 1994; Minden et al., 1994; Kyriakis and Avruch, 1996; Treisman, 1996), detailed studies of this point in PC12 cells provide clear evidence that NGF activation of c-Jun is mediated by ERKs (Leppa et al., 1998). Furthermore, these investigators obtained compelling evidence that c-Jun activation is a critical step in the pathway linking NGF receptor activation to neurite outgrowth; a constitutively active form of c-Jun is sufficient to trigger neurite outgrowth, and a dominant negative c-Jun construct blocks neurite outgrowth mediated by MEK (Leppa et al., 1998). 
In recent studies, we have obtained evidence that Egr proteins exert a proapoptotic effect in cerebellar granule cells by promoting c-Jun activation (Levkovitz and Baraban, 2001). Accordingly, we have, in this study, examined the relationship of Egr and c-Jun in mediating NGF-induced neurite outgrowth. Our results indicate that Egr family members also act upstream of c-Jun activation in this paradigm. Furthermore, these studies indicate that Egr proteins regulate c-Jun via a novel mechanism of action, formation of an Egr/c-Jun complex, rather than by their classical mode of action, regulating target gene expression via binding to the ERE.

\section{MATERIALS AND METHODS}

Reagents and plasmid constructs. NGF was obtained from Invitrogen (Gaithersburg, MD). UO126 (Promega, Madison, WI) was dissolved in DMSO to prepare a $10 \mathrm{~mm}$ stock solution. For studies with this drug, a comparable amount of DMSO was added to control wells. Preparation of ZnEgr3, an expression construct encoding the zinc finger DNA-binding domain of Egr3, has been described previously (O'Donovan et al., 2000; Levkovitz et al., 2001). Cytomegalovirus expression plasmids containing the zinc finger domains of Egr1(331-427) and Sp1(612-706), ZnEgr1 and ZnSp1, respectively (Chapman and Perkins, 2000), were provided by N. D. Perkins (Department of Biochemistry, University of Dundee, Dundee, UK). Expression plasmids encoding hemagglutinin (HA)- or His-tagged c-Jun, as well as a constitutively active c-Jun construct, c-Jun(Asp) (Leppa et al., 1998), were provided by D. Bohmann (European Molecular Biology Laboratory, Heidelberg, Germany). A constitutively active MEK1 expression construct, MEK(DD), was provided by M. Greenberg (Harvard Medical School, Cambridge, MA). The fulllength rat Egr1 expression plasmid was provided by J. Milbrandt (Washington University, St. Louis, MO).

To monitor expression of ZnEgr1, we prepared an N-terminal myctagged ZnEgr1 construct. To this end, we performed PCR with the full rat Egr1 cDNA as template and the appropriate primers. The PCR product was ligated into the PCR3.1-Uni vector (Invitrogen). To generate $\mathrm{ZnEgr} 1$ constructs with point mutations that impair binding to the Egr response element (ERE), ZnEgr1Y339G and ZnEgr1R358A, we used the QuikChange site-directed mutagenesis kit (Stratagene, La Jolla, CA) with the myc-tagged ZnEgr1 as the template. All inserts were sequenced in their entirety to verify that no inadvertent mutations were introduced and that the proper reading frame was achieved.

To monitor transcription mediated by the ERE, we used an ERE reporter plasmid provided by S. J. Kim (National Institutes of Health, Bethesda, MD) in which luciferase is under the control of an ERE located in the transforming growth factor $\beta 1$ promoter (phTG-5), as described previously (Levkovitz et al., 2001). To monitor transcription mediated by the transcription factors c-Jun, Elk-1, activating transcription factor 2 (ATF2), and cAMP response element-binding protein (CREB), we used the PathDetect system. This trans reporting system (Stratagene) uses two plasmids: one encodes a fusion protein composed of the activation domain of the transcription factor being studied linked to the GAL4 activation domain (pFA-Elk1, pFA-c-Jun, pFA-ATF2, and pFA-CREB); and the other plasmid, Pfr-Luc, contains a luciferase reporter construct under the control of a GAL4 response element. To monitor transcription mediated by activator protein-1 (AP-1), we used the PathDetect AP-1 cis reporting system (Stratagene). The green fluorescent protein (GFP) expression plasmid was obtained from Clontech (Palo Alto, CA).

Cell culture. hEK293 cells were maintained in 10-cm-diameter dishes at $37^{\circ} \mathrm{C}$ in $5 \% \mathrm{CO}_{2}$ in DMEM supplemented with $10 \%$ fetal bovine serum, $2 \mathrm{~mm}$ glutamine, and a $50 \mathrm{U} / \mathrm{ml}$ penicillin-streptomycin mixture. PC12 cells were maintained in medium containing DMEM, $10 \%$ fetal calf serum, $5 \%$ horse serum, and $1 \%$ penicillin-streptomycin in an atmosphere of $5 \% \mathrm{CO}_{2}$ and $37^{\circ} \mathrm{C}$.

Reporter assays. To monitor transcription mediated by the ERE, cells were cultured in six-well plates and transfected with one of the reporter plasmids (1-1.5 $\mu \mathrm{g} /$ well) using either the Gene-PORTER2 (Gene Therapy Systems) or LipofectAMINE (Invitrogen) along with expression plasmids as indicated $(0.1-1 \mu \mathrm{g})$ and either GFP $(0.4 \mu \mathrm{g})$ or $\beta$-galactosidase $(\beta$-Gal; $50 \mathrm{ng})$ expression plasmids. Unless indicated otherwise, the ZnEgr1, ZnEgr1(Y339G), ZnEgr1(R358A), ZnEgr3, Sp-1, ZnSp-1, MEK(DD), HA-c-Jun, HA-c-Jun(Asp), and His-c-Jun plasmids were used at $1 \mu \mathrm{g} /$ well, and "control" cells were transfected with the same amount of empty vector. In reporter assays monitoring the response to NGF, cells were harvested $6-8 \mathrm{hr}$ after addition of NGF (100 $\mathrm{ng} / \mathrm{ml}$ ). For the GAL4/Elk1, GAL4/c-Jun, GAL4/ATF2, and GAL4/ CREB reporter assays, cells were transfected with both Pfr-Luc $(1 \mu \mathrm{g})$ and one of the following plasmids $(50-100 \mathrm{ng})$ : pFA-Elk1, pFA-c-Jun, pFA-ATF2, or pFA-CREB. Luciferase activity was measured $2 \mathrm{~d}$ after transfection. Cells were rinsed twice with warm PBS, harvested in $1 \times$ reporter lysis buffer (Promega), and placed in $1.5 \mathrm{ml}$ tubes on ice. Extracts were vortexed for $10 \mathrm{sec}$ and centrifuged for $5 \mathrm{~min}$ at $14,000 \times$ $g$. Supernatants were collected, aliquoted, and used for both the luciferase (Promega) and luminescent $\beta$-Gal (Clontech) assays, conducted according to the manufacturers' protocols. For each well, both luciferase and $\beta$-Gal assays were performed in triplicate, and average values were used for further analysis. To help control for variability in transfection efficiency, $\beta$-Gal activity or the number of GFP-positive cells was used to normalize the luciferase values obtained. In each reporter experiment, three or more sister wells were transfected with the constructs being assayed. All reporter assays were performed in at least two independent experiments.

Neurite outgrowth assay. As described previously (Levkovitz et al., 2001), PC12 cells were plated in six-well plates precoated with poly-Dlysine at a confluence of $50-70 \%, \sim 1.0-1.5 \times 10^{5} \mathrm{cells} / \mathrm{cm}^{2}$, and then cotransfected with the GFP plasmid and the expression plasmid(s) being assayed at a stoichiometry of 1:5 to increase the likelihood that GFPpositive cells express the construct being evaluated. On the basis of GFP detection with standard fluorescence microscopy, transfection efficiency was in the range of $5-30 \%$. Neurite outgrowth was assessed $48 \mathrm{hr}$ after addition of NGF (50-100 ng/ml). Processes longer than twice the diameter of the cell body were scored as neurites. To evaluate effects on neurite outgrowth, GFP-positive cells were scored in 10 fields from each of two wells. Morphological effects were evaluated in at least two independent experiments.

Immunoblotting. Cell extracts were harvested in lysis buffer containing (in mM): 20 HEPES, 10 EGTA, 40 glycerophosphate, $2.5 \mathrm{MgCl}_{2}$, and 2 sodium orthovanadate, supplemented with freshly added $1 \mathrm{~mm}$ dithiothreitol, $10 \mathrm{mg} / \mathrm{ml}$ leupeptin, $1 \mathrm{mg} / \mathrm{ml}$ aprotinin, and $1 \mathrm{~mm}$ phenylmethylsulfonyl fluoride. The cell extracts were clarified by centrifugation, and $20-40 \mu \mathrm{g}$ of supernatant protein from each sample was processed for immunoblotting with one of the following antibodies: Egr1 (C-19, 0.2 $\mu \mathrm{g} / \mathrm{ml}$; Santa Cruz Biotechnology, Santa Cruz, CA), c-Jun (D-11, 0.4 $\mu \mathrm{g} / \mathrm{ml}$; Santa Cruz Biotechnology), His $(0.2 \mu \mathrm{g} / \mathrm{ml}$; Invitrogen $)$, HA (12CA5, $1 \mu \mathrm{g} / \mathrm{ml}$; Roche Molecular Biochemicals, Indianapolis, IN), or myc $(0.2 \mu \mathrm{g} / \mathrm{ml}$; Invitrogen).

Immunoprecipitation. Extracts were prepared using the same procedure described for immunoblotting and then incubated with protein A-Sepharose beads (Pierce, Rockford, IL) for $1 \mathrm{hr}$ at $4^{\circ} \mathrm{C}$. After these beads were pelleted, Egr1 antibody (C-19, $0.4 \mu \mathrm{g} / \mathrm{ml}$; Santa Cruz Biotechnology) that had been preincubated with protein A-Sepharose beads was added to the precleared supernatant. After an additional $1 \mathrm{hr}$ incubation, beads were pelleted by centrifugation in a microfuge and then processed for immunoblot analysis.

Nickel chelate chromatography. hEK293T cells expressing His-c-Jun were harvested in lysis buffer $\left(50 \mathrm{~mm} \mathrm{NaH}_{2} \mathrm{PO}_{4}, 300 \mathrm{~mm} \mathrm{NaCl}, 10 \mathrm{~mm}\right.$ imidazole, and $1 \%$ Triton X-100 supplemented with freshly added $1 \mathrm{~mm}$ dithiothreitol, $10 \mu \mathrm{g} / \mathrm{ml}$ leupeptin, $1 \mu \mathrm{g} / \mathrm{ml}$ aprotinin, and $1 \mathrm{~mm}$ phenylmethylsulfonyl fluoride, $\mathrm{pH}$ 8.0). Extracts were incubated with $\mathrm{Ni}$ nitrilotriacetic acid resin (Qiagen, Hilden, Germany) for $1 \mathrm{hr}$ at $4^{\circ} \mathrm{C}$. The resin was washed extensively with buffer (in mM: $50 \mathrm{NaH}_{2} \mathrm{PO}_{4}, 300 \mathrm{NaCl}$, and 20 imidazole supplemented with freshly added $1 \mathrm{~mm}$ dithiothreitol, $10 \mu \mathrm{g} / \mathrm{ml}$ leupeptin, $1 \mu \mathrm{g} / \mathrm{ml}$ aprotinin, and $1 \mathrm{~mm}$ phenylmethylsulfonyl fluoride, $\mathrm{pH}$ 8.0) and then eluted with a buffer containing a high concentration of imidazole (in mM: $50 \mathrm{NaH}_{2} \mathrm{PO}_{4}, 300 \mathrm{NaCl}$, and $250 \mathrm{imi}-$ dazole supplemented with freshly added $1 \mathrm{~mm}$ dithiothreitol, $10 \mu \mathrm{g} / \mathrm{ml}$ leupeptin, $1 \mu \mathrm{g} / \mathrm{ml}$ aprotinin, and $1 \mathrm{~mm}$ phenylmethylsulfonyl fluoride, $\mathrm{pH}$ 8.0). Eluted proteins were separated by SDS-PAGE and then processed for immunoblotting.

Data analysis. Differences between experimental groups were analyzed for statistical significance using the Student's $t$ test program in SPSS version 8.0 (SPSS, Inc., Chicago, IL).

\section{RESULTS}

\section{Egr inhibitor construct acts upstream of c-Jun}

To help determine whether Egr family members act upstream or downstream of c-Jun in the signaling pathway linking NGF re- 


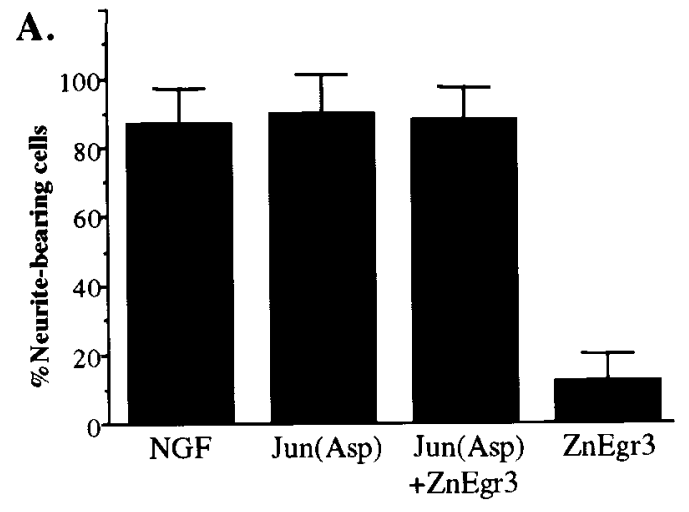

B.

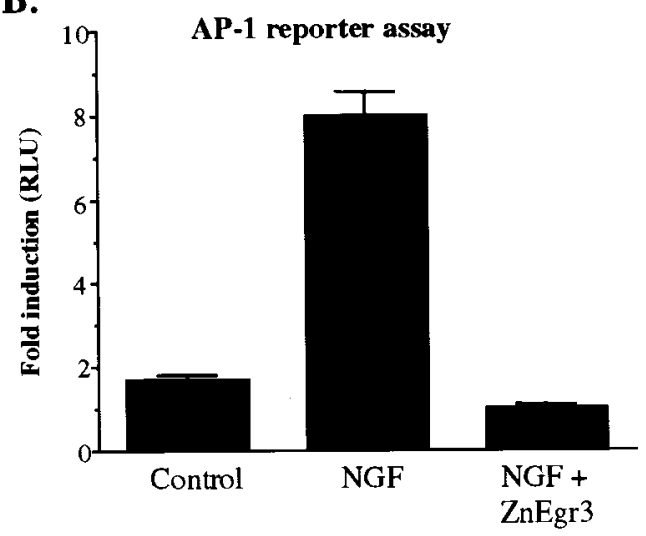

Figure 1. The Egr inhibitor construct $\mathrm{ZnEgr} 3$ acts upstream of c-Jun. A, The Egr inhibitor ZnEgr3 does not block the ability of a constitutively active c-Jun construct, c-Jun(Asp), to induce neurite outgrowth. In these studies, PC12 cells were transfected with a GFP expression plasmid, and the expression plasmids are listed below each bar. As shown in the left bar, nearly all cells transfected with GFP extend neurites after exposure to NGF $(100 \mathrm{ng} / \mathrm{ml})$. A comparable response is induced by c-Jun(Asp) in the absence of NGF. ZnEgr3 does not reduce the percentage of neuritebearing cells induced by c-Jun(Asp). The low percentage of cells that extend neurites after transfection with $\mathrm{ZnEgr} 3$ is comparable with that seen in control cells not exposed to NGF (data not shown). In this set of experiments, cells were treated with NGF $36 \mathrm{hr}$ after performing the transfection procedure, and then GFP-positive cells were scored for neurite outgrowth $2 \mathrm{~d}$ after NGF treatment. Similar results were obtained in three independent experiments. $B$, The Egr inhibitor ZnEgr3 blocks NGF stimulation of an AP-1 reporter construct. PC12 cells were transfected with an AP-1/luciferase reporter plasmid and either the ZnEgr3 expression plasmid or the corresponding amount of empty vector. Cells were treated with NGF $(100 \mathrm{ng} / \mathrm{ml}) 36 \mathrm{hr}$ after transfection and then processed for luciferase assays $6 \mathrm{hr}$ after NGF exposure. NGF produces a robust stimulation of AP-1 reporter activity (Control vs NGF; $p<0.02$ ) that is suppressed by $\mathrm{ZnEgr3}$ ( $N G F$ vs $N G F+Z n E g r 3 ; p<0.007)$. Error bars shown in this and subsequent figures indicate SEM. Similar results were obtained in three independent experiments. $R L U$, Relative luciferase units.

ceptor activation to neurite outgrowth, we assessed whether a dominant negative Egr construct, ZnEgr3 (Levkovitz et al., 2001), is able to block the ability of a constitutively active c-Jun construct, c-Jun(Asp), to induce neurite outgrowth (Leppa et al., 1998). As expected, we found that c-Jun(Asp) induces neurite outgrowth in a high percentage of transfected cells, comparable with the level observed after NGF treatment. However, the dominant negative Egr inhibitor ZnEgr3 does not inhibit neurite outgrowth induced by c-Jun(Asp) (Fig. $1 A$ ). Because these findings indicate that Egr family members do not act downstream of
c-Jun, we proceeded by evaluating the alternative possibility, i.e., that they exert their critical influence on NGF-induced neurite outgrowth by acting upstream of c-Jun activation.

To test this possibility, we asked whether the Egr inhibitor blocks the ability of NGF to stimulate expression of a luciferase reporter gene that is placed under the control of a tandem repeat of AP-1 response elements. We found that the Egr inhibitor construct abolishes the ability of NGF to stimulate this reporter system (Fig. $1 B$ ). The robust inhibitory effect of $\mathrm{ZnEgr3}$ cannot be attributed to nonspecific suppression of protein synthesis or luciferase activity, because we have found previously that the Egr inhibitor construct does not block the ability of NGF to stimulate a serum response element reporter (Levkovitz et al., 2001). Thus, these findings indicate that the Egr inhibitor construct blocks neurite outgrowth by acting upstream of c-Jun.

\section{Egr inhibitor blocks c-Jun activation}

In PC12 cells, NGF enhances AP-1-mediated transcription via two distinct mechanisms, induction and activation (Leppa et al., 1998). Induction refers to its ability to stimulate expression of protein components of the AP-1 complex; activation refers to its ability to stimulate the transcriptional activity of c-Jun-containing complexes by triggering phosphorylation of the $\mathrm{N}$-terminal activation domain of c-Jun. To test the possibility that the Egr inhibitor construct might act by blocking activation of c-Jun induced by NGF, we examined the effect of the Egr inhibitor construct on a reporter assay system that is designed to monitor transcription mediated by the N-terminal activation domain of c-Jun. In this reporter system, cells are transfected with two plasmids; one encodes a chimeric protein containing the N-terminal activation domain of c-Jun fused to the DNA-binding domain of GAL4, and the other contains a luciferase reporter gene under the control of GAL4 response elements. In these studies, we found that the Egr inhibitor construct markedly inhibits the ability of NGF to stimulate this reporter system (Fig. $2 A$ ).

To assess the specificity of this inhibitory effect, we also examined the effect of the Egr inhibitor construct on the ability of NGF to stimulate transcription mediated by the activation domains of ATF2 and CREB, two other transcription regulatory factors that are activated by phosphorylation (Gupta et al., 1995; Van Dam et al., 1995; Shaywitz and Greenberg, 1999). For these assays, we used reporter systems similar to that used to monitor activation of c-Jun. Expression plasmids encoding chimeric proteins containing the activation domain of ATF2 or CREB fused to the GAL4 DNA-binding domain were cotransfected with a luciferase reporter gene driven by GAL4 response elements. In contrast to its strong inhibitory effect on c-Jun activation by NGF, the Egr inhibitor construct exerts little effect on activation of ATF2 or CREB by NGF (Fig. 2B). In addition, we have, in a previous study (Levkovitz et al., 2001), demonstrated that the Egr inhibitor construct does not block the ability of NGF to stimulate an Elk1/GAL4 reporter in PC12 cells, providing additional evidence that its effects on c-Jun activation are selective.

Although these specificity studies indicate that the Egr inhibitor selectively suppresses c-Jun activation, it is conceivable that this effect is a general feature of zinc finger DNA-binding domains rather than being specifically related to blocking the activity of Egr family members. To address this question, we examined whether the closely related zinc finger DNA-binding domain found in Sp1 (ZnSp1; Nardelli et al., 1991) mimics the effects of the Egr inhibitor construct and found that it does not (Fig. 2B). To check whether this suppressive effect is shared by the zinc 

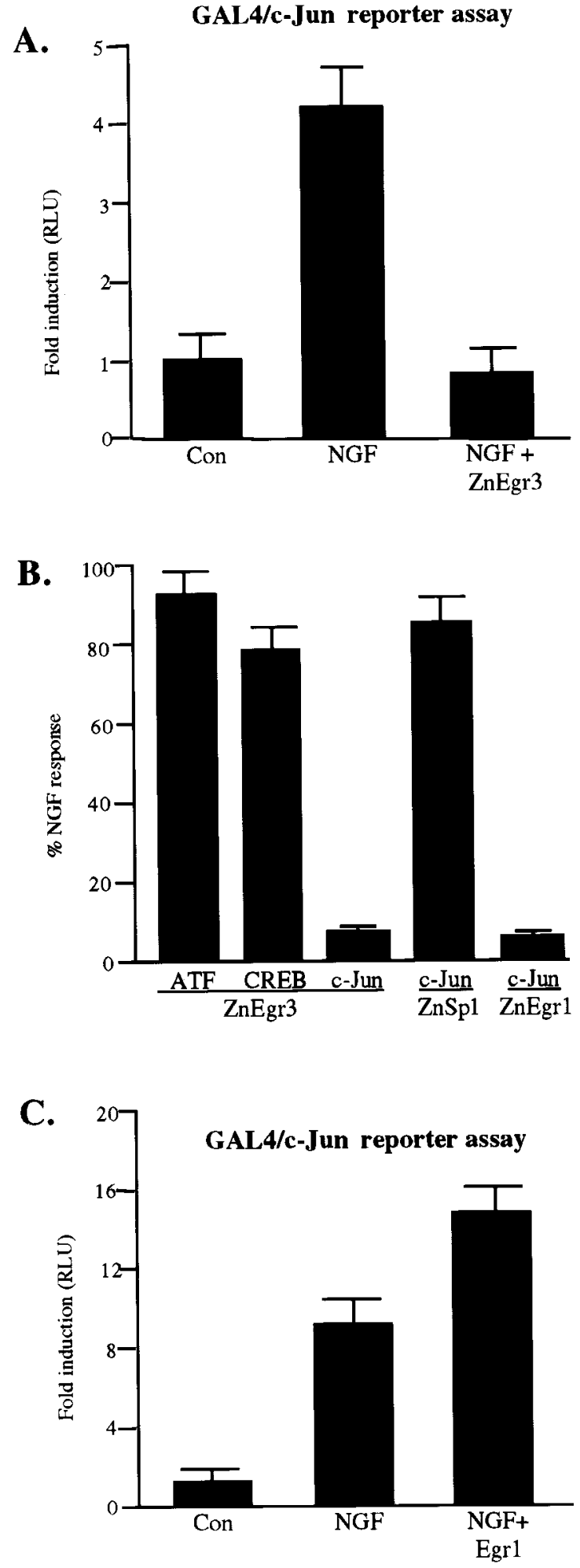

Figure 2. Selective blockade of c-Jun activation by Egr inhibitor constructs. $A, \mathrm{ZnEgr} 3$ blocks NGF stimulation of the GAL4/c-Jun reporter system. PC12 cells were transfected with a GAL4/luciferase reporter plasmid and an expression vector encoding a chimeric protein composed of the GAL4 DNA binding domain and the c-Jun N-terminal activation domain. One group of cells was also transfected with the $\mathrm{ZnEgr3}$ plasmid. Cells were treated with NGF $36 \mathrm{hr}$ after transfection and then processed for luciferase assays $6 \mathrm{hr}$ later. NGF stimulates the activity of the GAL4/ c-Jun reporter [control (Con) vs NGF; $p<0.05$ ], and this effect is blocked by ZnEgr3 ( $N G F$ vs $N G F+Z n E g r 3 ; p<0.05)$. Similar results were finger domains found in other Egr family members, we examined the effect of a truncated Egr1 construct, ZnEgr1, which contains the corresponding zinc finger DNA-binding domain located in Egr1. As expected, we found that ZnEgr1 mimics the ability of the ZnEgr3 construct to suppress c-Jun activation (Fig. 2B). Thus, these studies indicate that the highly conserved zinc finger domain shared by Egr family members selectively suppresses c-Jun activation.

An implicit assumption regarding the Egr inhibitor constructs is that they exert their effects by blocking the action of endogenous Egr family members that are expressed in PC12 cells. Thus, our findings predict that full-length Egr family members, such as Egr1, which is strongly induced in PC12 cells by NGF, should have a stimulatory effect on c-Jun activation. To test this prediction, we examined the effect of Egr1 on the GAL4/c-Jun reporter assay. We found that Egr1 does not stimulate the GAL4/c-Jun reporter system in the absence of NGF. However, Egr1 enhances c-Jun activation by NGF (Fig. 2C). Thus, these findings support our assumption that the Egr inhibitor constructs suppress c-Jun activation by blocking the actions of endogenous Egr family members.

\section{Egr inhibitor acts downstream of the MEK/ERK cascade}

Because these studies demonstrate that the Egr family plays a key role in regulating c-Jun activation, we turned our attention to determining which portion of the signaling cascade linking NGF receptor activation to c-Jun activation is influenced by the Egr family. Previous studies have provided compelling evidence that the MEK/ERK cascade, which is robustly activated by NGF receptor stimulation, plays a primary role in mediating c-Jun activation in PC12 cells (Leppa et al., 1998). Thus, although ERKs are notoriously poor at phosphorylating the $\mathrm{N}$ terminus of c-Jun in vitro compared with JNKs, ERKs mediate this response to NGF in PC12 cells. To confirm this point, we checked whether NGF stimulation of the GAL4/c-Jun reporter assay is blocked by UO126, a selective inhibitor of MEK (Favata et al., 1998). Consistent with previous results (Leppa et al., 1998), we found that UO126 completely suppresses the ability of NGF to stimulate the GAL4/c-Jun reporter system (Fig. $3 A$ ).

Because the MEK/ERK cascade mediates c-Jun activation induced by NGF, we wanted to determine whether the Egr inhibitor construct suppresses c-Jun activation by acting upstream

\footnotetext{
$\leftarrow$

obtained in three independent experiments. $B$, Selectivity studies. The selectivity of the effect shown in $A$ was analyzed in two ways: (1) ZnEgr3 was tested against NGF stimulation of activation domains present in ATF2 and CREB; and (2) other zinc finger domains, ZnSp1 and ZnEgr1, were tested against NGF stimulation of the c-Jun activation domain. As shown in the two left bars, ZnEgr3 does not inhibit NGF stimulation of GAL4/ATF2 or GAL4/CREB reporter systems. In addition, the zinc finger domain from Sp1, ZnSp1, does not mimic the ability of ZnEgr3 to suppress NGF stimulation of the GAL4/c-Jun reporter system, whereas the zinc finger domain from Egr1, ZnEgr1, does. Results shown were obtained in at least two independent experiments. $C$, Egr1 potentiates NGF activation of c-Jun. To examine the effect of Egr1 on c-Jun activation, PC12 cells were transfected with the GAL4/c-Jun reporter system plasmids along with either an Egr1 expression vector or the corresponding empty vector. On the second day after transfection, two groups of cells were exposed to NGF, as indicated below the bars, and then processed for luciferase assays $6 \mathrm{hr}$ later. Although Egr1 expression alone does not increase reporter activity (data not shown), it potentiates the effect of NGF $(N G F+E g r 1$ vs $N G F ; p<0.05)$. Similar results were obtained in three independent experiments. $R L U$, Relative luciferase units.
} 
A.
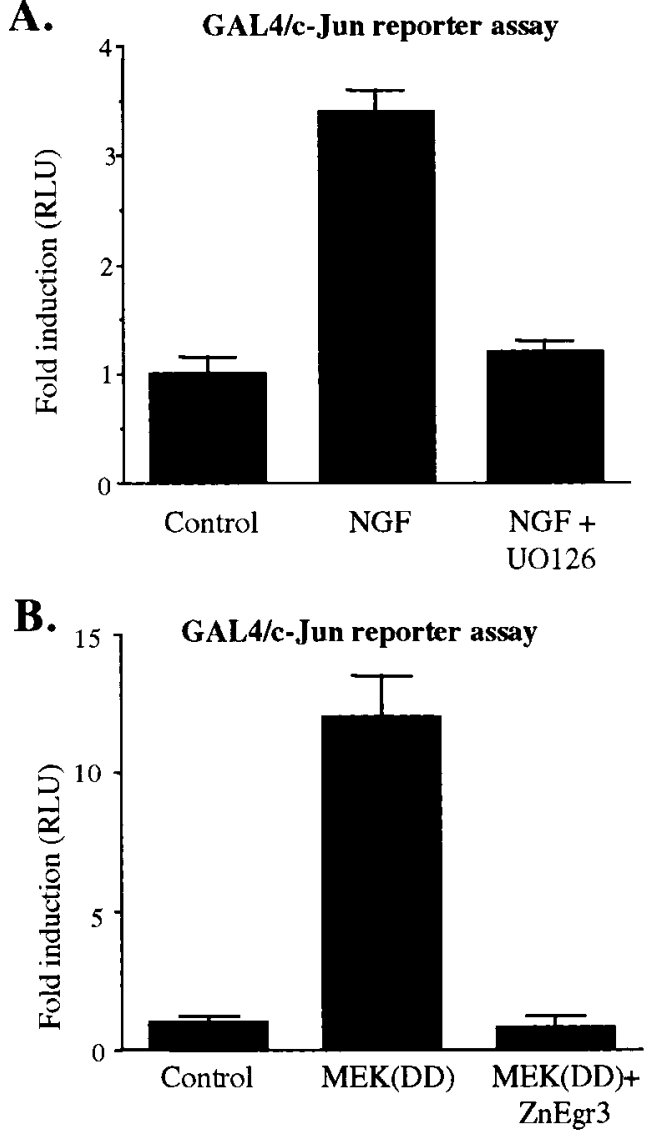

C.

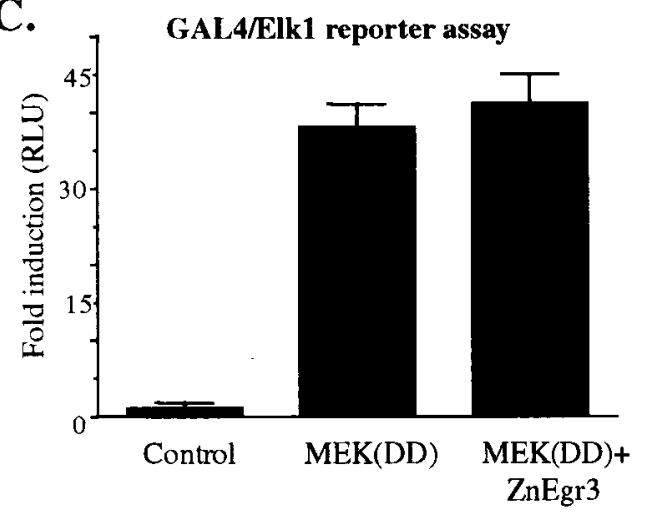

D.

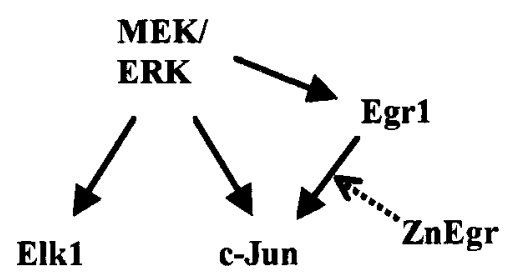

Figure 3. Egr inhibitor construct blocks MEK-induced activation of c-Jun selectively. A, Activation of c-Jun by NGF is mediated by the MEK/ERK cascade. Using the GAL4/c-Jun reporter system, we assessed the effect of the selective MEK inhibitor UO126 (15 $\mu \mathrm{M})$ on NGF activation of c-Jun. PC12 cells were treated with NGF $36 \mathrm{hr}$ after transfection with the reporter plasmids and then processed for luciferase assays $6 \mathrm{hr}$ after NGF treatment. Cells being treated with UO126 were preincubated with this drug 40 min before adding NGF. UO126 completely or downstream of MEK. To achieve this goal, we assessed the effect of ZnEgr3 on c-Jun activation induced by a constitutively active MEK construct, MEK(DD). In previous studies, we have shown that MEK(DD) mimics the ability of NGF to stimulate an ERE reporter in PC12 cells, indicating that Egr proteins could act distal to MEK (Levkovitz et al., 2001). To test this possibility, we assessed the effect of ZnEgr3 on the ability of MEK(DD) to induce c-Jun activation. We found that $\mathrm{ZnEgr3}$ completely abrogates this response, indicating that Egr proteins play a key role in allowing MEK to activate c-Jun (Fig. 3B).

To check whether ZnEgr3 exerts a general inhibitory effect on the MEK/ERK cascade or whether it selectively affects its ability to activate c-Jun, we assessed the effect of this Egr inhibitor construct on the ability of MEK(DD) to activate Elk1, a transcription factor known to be regulated by ERK kinases (Gille et al., 1992; Marais et al., 1993; Johnson et al., 1997). In contrast to its blockade of c-Jun activation, ZnEgr3 does not affect Elk1 activation by MEK(DD) (Fig. 3C). Thus, these findings demonstrate that ZnEgr3 selectively affects c-Jun activation mediated by the MEK/ERK cascade (Fig. 3D). Furthermore, they suggest that the ability of NGF to elicit c-Jun activation is dependent on both activation of the MEK/ERK cascade and induction of Egr protein expression.

\section{Identification of an Egr1/c-Jun complex}

In considering how Egr proteins could control c-Jun activation elicited by NGF, we found it difficult to understand how newly induced Egr proteins could trigger changes in target gene expression quickly enough to influence this relatively rapid response. As reported by Leppa et al. (1998), c-Jun phosphorylation becomes detectable by 15-30 min after NGF exposure. Thus, although Egr1 protein is also induced that quickly by NGF (Milbrandt, 1987; Kumahara et al., 1999), it seems unlikely that there would be sufficient time for Egr target genes to mediate this effect. Accordingly, we considered an alternative view, i.e., that Egr family members might regulate c-Jun activation via protein-protein interactions rather than via their interaction with the ERE.

To investigate the possibility that Egr proteins associate with c-Jun, we conducted immunoprecipitation studies on extracts prepared from PC12 cells. Because basal levels of Egr1 are extremely low in these cells, we treated cells with NGF for 1 hr to

blocked stimulation of this reporter assay by NGF (NGF vs NGF+ UO126; $p<0.05)$. B, ZnEgr3 blocks MEK-induced activation of c-Jun. PC12 cells were transfected with the GAL4/c-Jun reporter plasmids and either empty vector (Control) or the other expression vectors indicated, i.e., a constitutively active MEK construct, MEK(DD), with or without ZnEgr3. Cells were processed for luciferase assays $2 \mathrm{~d}$ after transfection. Cotransfection of ZnEgr3 with MEK(DD) suppresses its ability to stimulate the GAL4/c-Jun reporter $[M E K(D D)$ vs $M E K(D D)+Z n E g r 3 ; p<$ 0.005]. $C, \mathrm{ZnEgr3}$ does not block MEK-induced activation of Elk1. To assess the selectivity of $\mathrm{ZnEgr3}$, parallel experiments were performed with the GAL4/Elk1 reporter system. In contrast to its marked suppression of GAL4/c-Jun reporter activity, ZnEgr3 does not inhibit GAL4/ Elk1 reporter activity. Results shown $A-C$ are representative of three independent experiments. $D$, Selective inhibition of c-Jun activation by $\mathrm{ZnEgr}$. The schematic diagram illustrates the selective inhibitory effect of ZnEgr on c-Jun activation. The constitutively active MEK construct, MEK(DD), activates both c-Jun and Elk1. However, ZnEgr selectively suppresses activation of c-Jun, indicating that it does not act as a general inhibitor of the MEK/ERK cascade. The diagram also shows that the $\mathrm{MEK} / \mathrm{ERK}$ pathway induces endogenous Egr protein expression. According to this model, activation of c-Jun by the MEK/ERK pathway is dependent on both its induction of Egr proteins and direct phosphorylation of c-Jun by ERK. $R L U$, Relative luciferase units. 
A.
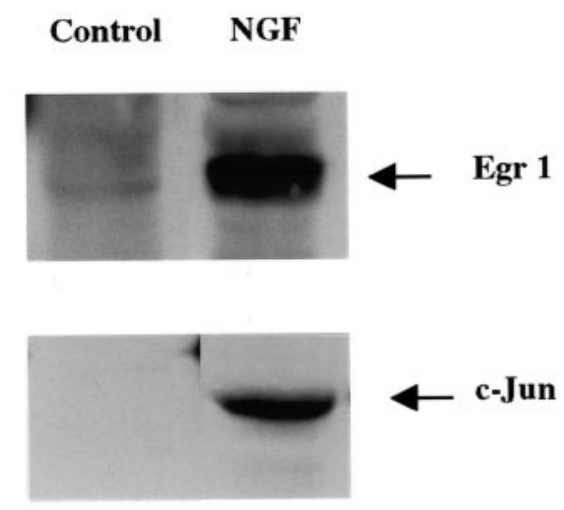

\section{PC 12 cells}

B.
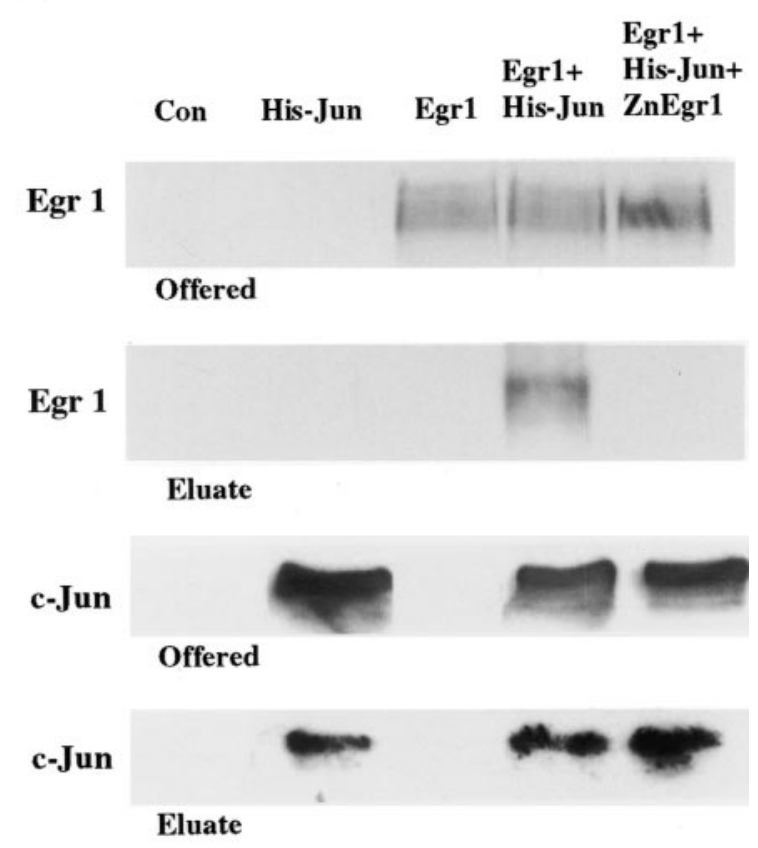

\section{hEK 293 Cells}

Figure 4. Coprecipitation of Egr1 and c-Jun. A, Endogenous Egr1 and c-Jun coprecipitate from PC12 cell extracts. Extracts were prepared from either control or NGF-treated (100 ng/ml, $1 \mathrm{hr}$ ) PC12 cells and processed for immunoprecipitation with Egr1 antibodies. Immunoblotting of pellets with antibodies to Egr1 or c-Jun demonstrate that these proteins coprecipitate from extracts of NGF-treated cells but not control cells, which have negligible levels of Egr1. B, Coprecipitation of Egr1 and c-Jun from hEK293 cells: inhibition by ZnEgr1. hEK293 cells were transfected with the expression vector(s) indicated above each lane. His-c-Jun and associated proteins were isolated from cell extracts by nickel chelate chromatography. Aliquots of the samples incubated with the resin (Offered) and eluted from the resin (Eluate) were processed for immunoblotting. Immunoblots probed with His antibodies confirm that c-Jun is expressed at comparable levels across different experimental groups and that the isolation procedure is effective. Furthermore, Egr1 immunoblots demonstrate that Egr1 is detected in the eluate from the nickel resin only when coexpressed with His-c-Jun. Furthermore, association of Egr1 with c-Jun is eliminated by cotransfection with $\mathrm{ZnEgr1}$. The results shown in $A$ and $B$ are representative of three independent experiments. Con, Control. induce Egr1 expression. Under these conditions, but not in control cells, we found that antibodies to Egr1 also precipitate c-Jun (Fig. 4A). To confirm that precipitation of c-Jun was attributable to its association with Egr1 rather than cross-reactivity of Egr1 antibodies with c-Jun, we also conducted coprecipitation studies using extracts of hEK293 cells that had been transfected with expression plasmids encoding His tagged-c-Jun, Egr1, or both (Fig. 4B). Using nickel chelate chromatography to isolate His-cJun, we found that Egr1 coelutes with c-Jun. Furthermore, we checked that its binding to the nickel resin is dependent on its coexpression with His-c-Jun. If the ability of Egr proteins to control c-Jun activation is mediated by formation of an Egr1/ c-Jun complex, then ZnEgr constructs that block c-Jun activation should interfere with formation of the complex. Consistent with this scenario, we found that the Egr dominant negative construct ZnEgr1 blocks association of Egr1 with c-Jun.

\section{Dissociation of ERE binding and suppression of c-Jun activation}

Although these studies demonstrate that the Egr inhibitor construct binds to c-Jun and blocks formation of the Egr1/c-Jun complex, this construct also blocks the ability of Egr proteins to regulate target gene expression via the ERE. Accordingly, these findings do not help distinguish between these alternative mechanisms. The relatively rapid time course of c-Jun phosphorylation after NGF stimulation favors a role for the Egr1/c-Jun complex. However, this line of evidence cannot be considered definitive, because it is conceivable that basal levels of Egr proteins, although they are extremely low, are sufficient to drive expression of one or more target genes that enable c-Jun activation to occur. Accordingly, we wanted to determine whether the ability of the Egr inhibitor to block c-Jun activation is dependent on its ability to bind to the ERE. To achieve this goal, we tested the effects of two mutant ZnEgr1 constructs containing point mutations, ZnEgr1(Y339G) and ZnEgr1(R358A), in residues that are essential for ERE binding (Matheny et al., 1994; Elrod-Erickson and Pabo, 1999).

After confirming that these mutant ZnEgr1 constructs are unable to block activation of the ERE reporter by NGF (Fig. $5 A$ ), we checked that they retain the ability to bind to the c-Jun complex (Fig. 5B). After this initial characterization of the mutant ZnEgr1 constructs, we tested their effects on NGF-induced activation of the GAL4/c-Jun reporter and found that they retain the ability to block this response (Fig. $5 C$ ). Accordingly, we infer that the ability of the Egr inhibitor construct to block c-Jun activation is not mediated by its blockade of ERE-mediated changes in target gene expression. Instead, these results favor the alternative view that it is mediated by its interaction with c-Jun. Last, we also checked the effects of the mutant ZnEgr1 constructs on NGF-induced neurite outgrowth (Fig. 5D). We found that they retain the ability to block this response to NGF, suggesting that the ability of ZnEgr to block c-Jun activation is sufficient to suppress neurite outgrowth, and that neither of these effects is dependent on blocking changes in target gene expression mediated via the ERE.

\section{DISCUSSION}

To help define the role of Egr proteins in mediating NGFinduced neurite outgrowth, we have investigated how a dominant negative Egr construct suppresses this response. Our analysis of the actions of $\mathrm{ZnEgr}$ has yielded several major findings. First, our results demonstrate that ZnEgr blocks neurite outgrowth by 
A.

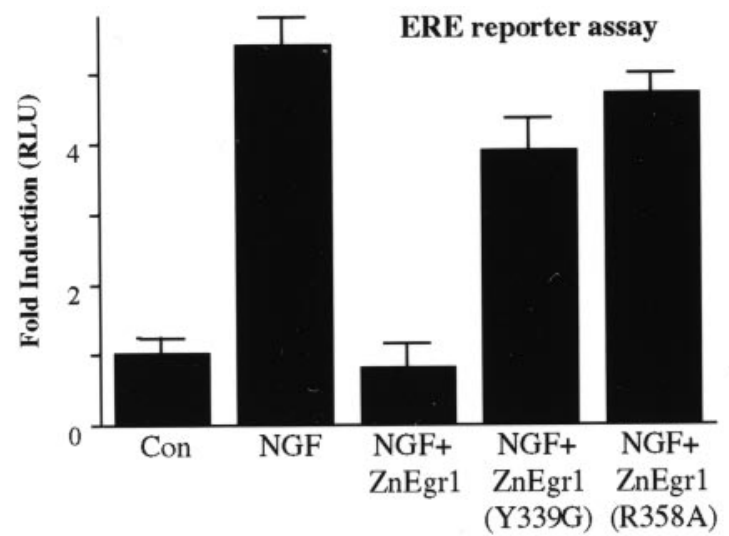

B.

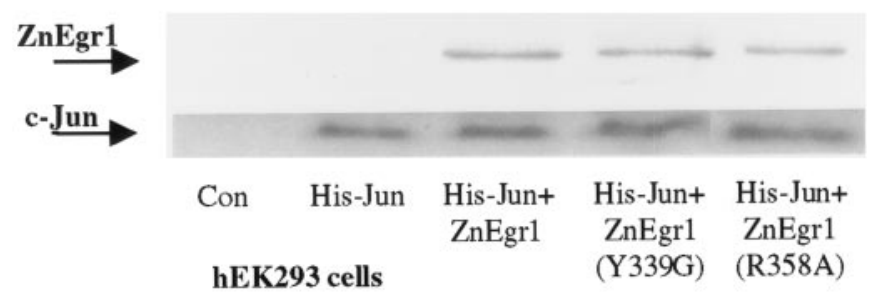

C.

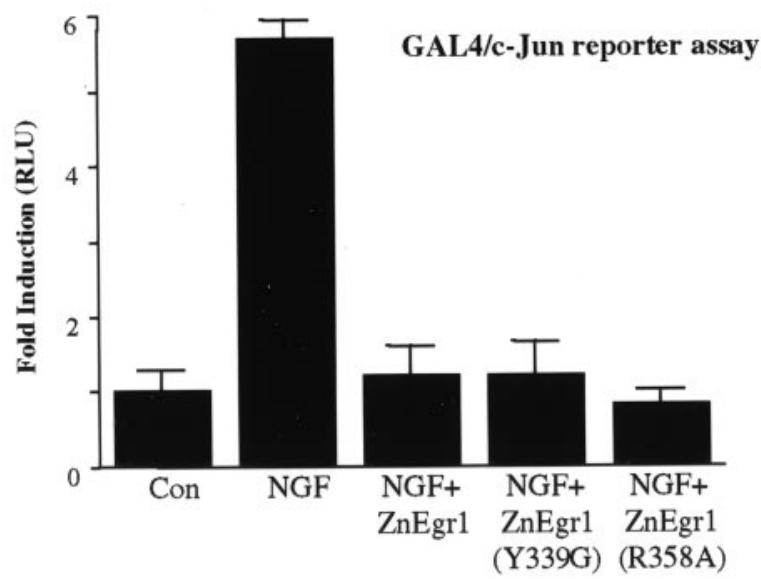

D.

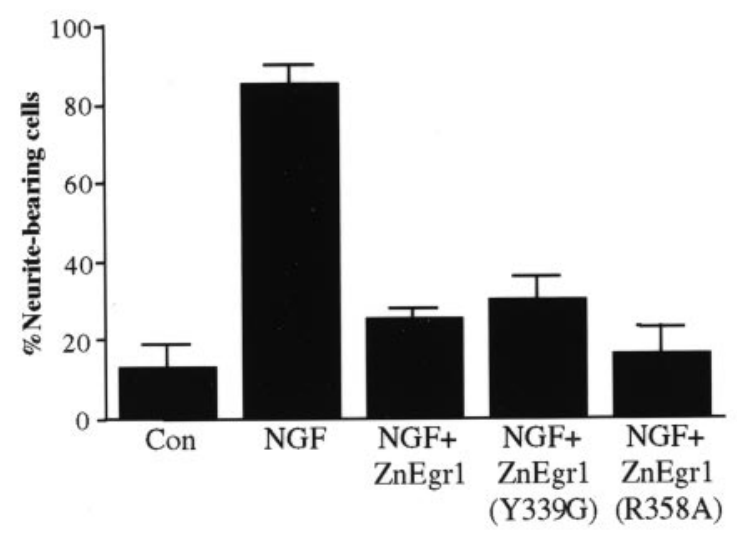

Figure 5. Mutations that disrupt ZnEgr1 binding to the ERE do not interfere with its suppression of c-Jun activation or neurite outgrowth. $A$, Effect of wild-type and mutant ZnEgr1 constructs on ERE reporter activity. To confirm that the point mutations introduced into ZnEgr1 block its ability to inhibit ERE reporter activity, these constructs (Y339 and R358A) or wild-type ZnEgr1 were transfected into PC12 cells along suppressing c-Jun activation, a key step in the signaling pathway linking NGF receptor stimulation to neurite outgrowth. Second, our studies with mutant $\mathrm{ZnEgr}$ constructs indicate that this domain suppresses c-Jun activation via its protein-protein interaction with c-Jun and not via its intended mode of action, binding to the ERE. Furthermore, because both Egr1 and ZnEgr1 bind to c-Jun and have opposing effects on c-Jun activation, we propose that Egr proteins promote c-Jun activation and neurite outgrowth via this novel mechanism rather than via their interaction with the ERE.

This parsimonious model is attractive for three reasons. First, it explains how mutant $\mathrm{ZnEgr1}$ constructs, which have negligible ERE-binding activity, suppress c-Jun activation and neurite outgrowth. Second, this direct mechanism fits well with the time course of Egr protein induction and c-Jun phosphorylation. In contrast, the alternative ERE-based model does not appear to leave sufficient time for Egr proteins to act indirectly via regulation of target gene expression. Third, the direct interaction of Egr proteins with c-Jun provides a convenient means of explaining how these proteins regulate c-Jun activation selectively, without affecting activation of Elk1, another ERK substrate.

Although NGF-induced activation of c-Jun is mediated by the MEK/ERK cascade, and the constitutively active MEK construct is able to induce Egr protein expression, it is important to point out that pharmacological blockade of MEK does not inhibit the ability of NGF to stimulate ERE reporter activity (Levkovitz et al., 2001). Thus, $\mathrm{ZnEgr}$ constructs and MEK inhibitors act on two distinct pathways (Fig. 6). The ability of MEK inhibitors to block c-Jun activation is not attributable to suppression of Egr protein induction, and, conversely, the blockade of c-Jun activation by $\mathrm{ZnEgr}$ cannot be attributed to a global suppression of the MEK/

with the ERE reporter plasmid. After 2 d, cells were exposed to NGF (100 $\mathrm{ng} / \mathrm{ml}$ ) to stimulate ERE reporter activity and then processed for luciferase assays $6 \mathrm{hr}$ later. In contrast to wild-type ZnEgr1, which suppresses ERE reporter activity induced by NGF (NGF vs $N G F+Z n E g r 1 ; p<$ 0.001), both mutant $\mathrm{ZnEgr1}$ constructs are unable to block this response. Similar results were obtained in two independent experiments. $B$, Effect of $\mathrm{ZnEgr1}$ mutations on the association of $\mathrm{ZnEgr1}$ with c-Jun. To check whether these mutant $\mathrm{ZnEgr1}$ constructs are still able to associate with c-Jun, the wild-type or mutant ZnEgr1 constructs were expressed with His-c-Jun in hEK293 cells. Cell extracts were then processed for nickel chelate chromatography, and proteins eluted from the resin were analyzed by immunoblotting. Because the ZnEgr1 constructs are myc-tagged, the presence of these constructs was detected by immunoblotting with myc antibodies (top panel). The presence of c-Jun in the eluate was confirmed by immunoblotting with His antibodies (bottom panel). $C$, ZnEgr1 mutants block c-Jun activation. To assess the ability of the mutant ZnEgr1 constructs to inhibit c-Jun activation by NGF, PC12 cells were transfected with either wild-type or mutant ZnEgr1 constructs along with the GAL4/ c-Jun reporter assay plasmids. Two days after transfection, cells were exposed to NGF (100 ng/ml) and then processed for luciferase assays $6 \mathrm{hr}$ later. NGF elicits a robust increase in c-Jun reporter activity that is suppressed by both wild-type and mutant ZnEgr1 constructs. Similar results were obtained in three independent experiments. $D$, ZnEgr1 mutant constructs block NGF-induced neurite outgrowth. To assess the effect of the ZnEgr1 mutations on NGF-induced neurite outgrowth, PC12 cells were transfected with either wild-type or mutant ZnEgr1 constructs along with a GFP expression vector. Two days after transfection, cells were treated with NGF $(100 \mathrm{ng} / \mathrm{ml})$, and then GFP-positive cells were scored for the presence of neurites $2 \mathrm{~d}$ later. Both the wild-type and mutant $\mathrm{ZnEgr1}$ constructs markedly suppress neurite outgrowth. Similar results were obtained in two independent experiments. Statistical analyses of the data shown in $C$ and $D$ confirm that the group treated with NGF is significantly different from each of the other experimental groups. Con, Control. $R L U$, Relative luciferase units. 


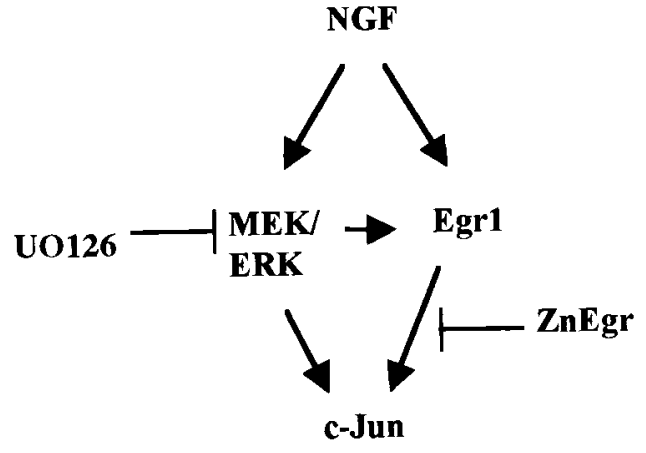

Figure 6. NGF activation of c-Jun: role of the MEK/ERK cascade and Egr proteins. The schematic diagram illustrates the signaling pathways linking NGF receptor stimulation with c-Jun activation. According to this model, c-Jun activation is dependent on both activation of the MEK/ ERK cascade and expression of Egr family members induced by NGF in PC12 cells, i.e., Egr1 and Egr4. Thus, c-Jun activation by NGF can be suppressed by selective inhibitors of either pathway, i.e., UO126 or ZnEgr constructs. An arrow connecting $M E K / E R K$ and Egrl has been included, because MEK(DD) stimulates the ERE reporter. In addition, an arrow connecting NGF directly to Egrl has been included, because previous studies indicate that NGF can induce Egr proteins in PC12 cells via a MEK-independent pathway (Kumahara et al., 1999; Levkovitz et al., 2001).

ERK cascade, because it does not affect activation of Elk1 by MEK(DD). Furthermore, in previous studies, we have confirmed that Elk1 activation induced by NGF is abolished by UO126 and not affected by ZnEgr (Levkovitz et al., 2001). Thus, together these results indicate that NGF induction of Egr proteins and stimulation of ERKs act in concert to mediate c-Jun activation.

The key features of this model of Egr action fit well with our previous findings indicating that Egr proteins play a critical role in mediating cerebellar granule cell apoptosis induced by potassium deprivation (Levkovitz and Baraban, 2001). In that study, we demonstrated that potassium deprivation induces Egr protein expression in these cells and that $\mathrm{ZnEgr}$ constructs block apoptosis in this paradigm. Furthermore, our analysis of Egr function in cerebellar granule cells indicated that Egr proteins act by potentiating c-Jun activation, a critical step in the signaling pathway linking potassium deprivation to apoptosis (Watson et al., 1998). As found in PC12 cells, transfection of an Egr1 expression plasmid does not increase c-Jun activity in cerebellar granule cells but does potentiate the rise in c-Jun activity induced by switching to low potassium. Thus, we infer that Egr proteins are not sufficient to stimulate c-Jun activity by themselves but work together with a cofactor, such as ERKs, to potentiate c-Jun activation. It is noteworthy that c-Jun activation in the potassium deprivation paradigm appears to be mediated by JNK or p38 mitogen-activated protein kinases (Watson et al., 1998; Yamagishi et al., 2001) and not ERKs. Thus, these findings indicate that Egr proteins play a general role in potentiating c-Jun activation by a variety of upstream kinases, not just ERKs.

Our inference that Egr proteins work in concert with ERKs in PC12 cells may be relevant to understanding the disparate phenotypic effects elicited by NGF and epidermal growth factor (EGF) in these cells; EGF elicits a proliferative response, whereas NGF triggers differentiation. This striking difference in phenotypic responses appears to be attributable to distinct patterns of ERK activation induced by these agents (Qiu and Green, 1992; Nguyen et al., 1993; Marshall, 1995; Yamada et al., 1996). Whereas EGF triggers a brief burst of ERK activation that lasts only a few minutes, NGF elicits sustained ERK activation that lasts for several hours. Although EGF, like NGF, also induces Egr gene expression (Kujubu et al., 1993), it appears likely that the transient ERK activation elicited by EGF is too short-lived to overlap with Egr protein expression. In contrast, the sustained ERK activation triggered by NGF would enable ERKs to collaborate with Egr proteins in mediating c-Jun activation. This proposal fits well with the observation in PC12 cells that NGF, but not EGF, stimulates AP-1 response elements located within the c-jun promoter (Groot et al., 2000).

Recent studies have focused attention on another major difference between NGF and EGF responses in these cells. NGF induces robust induction of Fra-2, whereas EGF does not (Boss et al., 2001). Accordingly, it may be interesting in future studies to examine whether suppression of Egr or c-Jun function or both blocks this delayed response to NGF or whether the increase in Fra-2 expression is mediated by a distinct signaling pathway.

Because the ZnEgr domain blocks the ability of full-length Egr1 to associate with c-Jun, it is tempting to assume that it exerts its suppressive effect by disrupting this interaction. An interesting corollary of this assumption would be that c-Jun activation is strongly dependent on its association with Egr proteins. However, at present, we cannot rule out the possibility that the $\mathrm{ZnEgr}$ domain exerts a direct inhibitory effect on c-Jun activation, i.e., that it possess inverse agonist activity. In this scenario, the profound suppression of c-Jun activation by $\mathrm{ZnEgr}$ would exceed that produced by passively blocking association of endogenous Egr proteins with c-Jun. According to this view, association of full-length Egr proteins with c-Jun potentiates its activation, whereas disruption of this complex would block this enhancement. However, a key feature of the "inverse agonist" model is that Egr protein would not be required for c-Jun activation to occur.

Because we have found that $\mathrm{ZnEgr}$ does not block the ability of c-Jun(Asp) to trigger neurite outgrowth or to stimulate AP-1mediated transcription (Y. Levkovitz, unpublished observations), these results suggest that formation of the Egr/c-Jun complex may regulate c-Jun activation by facilitating or stabilizing c-Jun phosphorylation. However, it may also regulate the localization or stability of c-Jun, an alternative possibility that needs to be considered as well.

Despite these uncertainties regarding the precise mode of action of $\mathrm{ZnEgr}$, our findings provide compelling evidence that c-Jun activation is a key downstream target of Egr proteins and that the Egr zinc finger domain mediates its interaction with c-Jun, as well as with the ERE. Of note, there are several reports that zinc finger domains of the $\mathrm{C}_{2} \mathrm{H}_{2}$ type found in Egr proteins mediate protein-protein interactions between transcription factors (Merika and Orkin, 1995; Srivastava et al., 1998; Chapman and Perkins, 2000). Accordingly, it is reasonable to infer that the ZnEgr domain enables Egr proteins to exert downstream effects via either protein-protein or protein-DNA interactions.

Because the Egr zinc finger domain mediates binding to the ERE and to a c-Jun complex, one possibility that needs to be considered is that the Egr/c-Jun complex detected biochemically represents binding of Egr and c-Jun to segments of DNA that contain cis elements recognized by both these proteins. However, it is difficult to argue that formation of the Egr/c-Jun complex is mediated by Egr binding to the ERE, because ZnEgr1 mutants with negligible affinity for the ERE still coprecipitate with c-Jun. In addition, we have also found that Egr does not coprecipitate with c-Jun(Asp) (Levkovitz, unpublished observations), although 
this construct binds to AP-1 sites with high affinity. Together, these findings support the conclusion that the Egr zinc finger domain mediates two distinct binding interactions.

Recent studies in PC12 cells suggest that p35, an activator of cdk5, is a target gene regulated by Egr1 that mediates NGFinduced neurite outgrowth (Harada et al., 2001). Accordingly, our findings raise the possibility that Egr proteins regulate $\mathrm{p} 35$ via their interaction with c-Jun, ERE, or both. It is important to emphasize that our studies demonstrate that blockade of EREmediated transcription is not needed to suppress NGF-induced neurite outgrowth. However, they do not rule out the formal possibility that blockade of the ERE might be sufficient to inhibit this phenotypic response. Resolving this question will depend on developing Egr constructs that do not block c-Jun activation but retain the ability to inhibit ERE-mediated transcription.

In summary, our studies indicate that Egr proteins can function as coactivators of c-Jun. Thus, in addition to regulating target gene expression via binding to the ERE, they can also influence gene expression controlled by AP-1 sites via their interaction with c-Jun. Because Egr proteins have been implicated in a wide variety of phenotypic effects, ranging from Schwann cell and muscle spindle differentiation (Topilko et al., 1994; Tourtellotte and Milbrandt, 1998; Nagarajan et al., 2001) to learning and memory (Wei et al., 2000; Jones et al., 2001) and neuronal apoptosis (Catania et al., 1999; Park and Koh, 1999; Levkovitz and Baraban, 2001), it will be interesting to determine which of these cis elements or whether both mediate the effects of Egr proteins in these plasticity paradigms.

\section{REFERENCES}

Boss V, Roback JD, Young AN, Roback LJ, Vogt Weisenhorn DM, Medina-Flores R, Wainer BH (2001) Nerve growth factor, but not epidermal growth factor, increases Fra-2 expression and alters Fra-2/ JunD binding to AP-1 and CREB binding elements in pheochromocytoma (PC12) cells. J Neurosci 21:18-26.

Catania MV, Copani A, Calogero A, Ragonese GI, Condorelli DF, Nicoletti F (1999) An enhanced expression of the immediate early gene, Egr-1, is associated with neuronal apoptosis in culture. Neuroscience 91:1529-1538.

Chapman NR, Perkins ND (2000) Inhibition of the RelA(p65) NF-kB subunit by Egr-1. J Biol Chem 275:4719-4725.

Christy B, Nathans D (1989) DNA binding site of the growth factorinducible protein Zif268. Proc Natl Acad Sci USA 86:8737-8741.

Cowley S, Paterson H, Kemp P, Marshall CJ (1994) Activation of MAP kinase kinase is necessary and sufficient for PC12 differentiation and for transformation of NIH 3T3 cells. Cell 77:841-852.

Crosby SD, Puetz JJ, Simburger KS, Fahrner TJ, Milbrandt J (1991) The early response gene NGFI-C encodes a zinc finger transcriptional activator and is a member of the GCGGGGGCG (GSG) elementbinding protein family. Mol Cell Biol 11:3835-3841.

Derijard B, Hibi M, Wu I, Barrett T, Su B, Deng T, Karin M, Davis R (1994) JNK1: a protein kinase stimulated by UV-light and Ha-Ras that binds and phosphorylates the c-Jun activation domain. Cell 71: 1081-1091.

Elrod-Erickson M, Pabo CO (1999) Binding studies with mutants of Zif268. J Biol Chem 274:19281-19285.

Favata MF, Horiuchi KY, Manos EJ, Daulerio AJ, Stradley DA, Feeser WS, Van Dyk DE, Pitts WJ, Earl RA, Hobbs F, Copeland RA, Magolda RL, Scherle PA, Trzaskos JM (1998) Identification of a novel inhibitor of mitogen-activated protein kinase kinase. J Biol Chem 273:18623-18632.

Gashler A, Sukhatme VP (1995) Early growth response protein 1(Egr1): prototype of a zinc finger family of transcription factors. Prog Nucleic Acid Res Mol Biol 50:191-224.

Gille H, Sharrocks AD, Shaw PE (1992) Phosphorylation of transcription factor $\mathrm{p} 62^{\mathrm{TCF}}$ by MAP kinase stimulates ternary complex formation at c-fos promoter. Nature 358:414-417.

Groot M, Boxer LM, Thiel G (2000) Nerve growth factor and epidermal growth factor regulated gene transcription in PC12 pheochromocytoma and INS-1 insulinoma cells. Eur J Cell Biol 79:924-935.

Gupta S, Campbell D, Derijard B, Davis RJ (1995) Transcription factor ATF-2 regulation by the JNK signal transduction pathway. Science 267:389-393.

Harada T, Morooka T, Ogawa S, Nishida E (2001) ERK induces p35, a neuron-specific activator of Cdk5, through induction of Egr1. Nat Cell Biol 3:453-459.

Johnson CM, Hill CS, Chawla S, Treisman R, Bading H (1997) Calcium controls gene expression via three distinct pathways that can function independently of the Ras/mitogen-activated protein kinases (ERKs) signaling cascade. J Neurosci 17:6189-6202.

Jones MW, Errington MS, French PJ, Fine A, Bliss TVP, Garel S, Charnay P, Bozon B, Laroche S, Davis S (2001) A requirement for the immediate early gene zif268 in the expression of late LTP and longterm memories. Nat Neurosci 4:289-296.

Kujubu DA, Stimmel JB, Law RE, Herschman HR, Clarke S (1993) Early responses of PC12 cells to NGF and EGF: effect of K252a and 5 'methylthioadenosine on gene expression and membrane protein methylation. J Neurosci Res 36:58-65.

Kumahara E, Ebihara T, Saffen D (1999) Nerve growth factor induces zif268 gene expression via MAPK-dependent and -independent pathways in PC12D cells. J Biochem 125:541-553.

Kyriakis JM, Avruch J (1996) Protein kinase cascades activated by stress and inflammatory cytokines. BioEssays 18:567-577.

Leppa S, Saffrich R, Ansorge W, Bohmann D (1998) Differential regulation of c-Jun by ERK and JNK during PC12 cell differentiation. EMBO J 17:4404-4413.

Levkovitz Y, Baraban JM (2001) A dominant negative inhibitor of the Egr family of transcription regulatory factors suppresses cerebellar granule cell apoptosis by blocking c-Jun activation. J Neurosci 21:5893-5901.

Levkovitz Y, O'Donovan KJ, Baraban JM (2001) Blockade of NGFinduced neurite outgrowth by a dominant negative inhibitor of the Egr family of transcription regulatory factors. J Neurosci $21: 45-52$.

Marais R, Wynne J, Treisman R (1993) The SRF accessory protein Elk-1 contains a growth factor-regulated transcriptional activation domain. Cell 73:381-393.

Marshall CJ (1995) Specificity of receptor tyrosine kinase signaling: transient versus sustained extracellular signal-related kinase activation. Cell 80:179-185.

Matheny C, Day ML, Milbrandt J (1994) The nuclear localization signal of NGFI-A is located within the zinc finger DNA binding domain. J Biol Chem 269:8176-8181.

Merika M, Orkin SH (1995) Functional synergy and physical interactions of the erythroid transcription factor GATA-1 with the Kruppel family proteins Sp1 and EKLF. Mol Cell Biol 15:2437-2447.

Milbrandt J (1987) A nerve growth factor-induced gene encodes a possible transcriptional regulatory factor. Science 238:797-799.

Minden A, Lin A, Smeal T, Derijard B, Cobb M, Davis R, Karin M (1994) c-Jun N-terminal phosphorylation correlates with activation of the JNK subgroup but not the ERK subgroup of mitogen-activated protein kinases. Mol Cell Biol 14:6683-6688.

Nagarajan R, Svaren J, Le N, Araki T, Watson M, Milbrandt J (2001) EGR2 mutations in inherited neuropathies dominant-negatively inhibit myelin gene expression. Neuron 30:355-368.

Nardelli J, Gibson TJ, Vesque C, Charnay P (1991) Base sequence discrimination by zinc finger DNA binding domains. Nature 349:175-178.

Nguyen TT, Scimeca J-C, Filoux C, Peraldi P, Carpentier J-L, Van Obberghen E (1993) Co-regulation of the mitogen-activated protein kinase, extracellular signal-regulated kinase 1 , and the $90 \mathrm{kDa}$ ribosomal S6 kinase in PC12 cells. J Cell Biol 268:9803-9810.

O'Donovan KJ, Tourtellotte WG, Milbrandt J, Baraban JM (1999) The EGR family of transcription-regulatory factors: progress at the interface of molecular and systems neuroscience. Trends Neurosci 22:167-173

O'Donovan KJ, Levkovitz Y, Baraban JM (2000) Functional comparison of Egr3 transcription factor isoforms: identification of an activation domain in the $\mathrm{N}$-terminal segment absent from Egr3, a major isoform expressed in brain. J Neurochem 75:1352-1357.

Pang L, Sawada T, Decker SJ, Saltiel AR (1995) Inhibition of MAP kinase kinase blocks the differentiation of PC12 cells induced by nerve growth factor. J Biol Chem 270:13585-13588.

Papavassiliou AG, Treier M, Bohmann D (1995) Intramolecular signal transduction in c-Jun. EMBO J 14:2014-2019.

Park JA, Koh JY (1999) Induction of an immediate early gene egr-1 by zinc through extracellular signal-regulated kinase activation in cortical culture: its role in zinc-induced neuronal death. J Neurochem 73:450-456.

Pulverer BJ, Kyriakis JM, Avruch J, Nikolakaki E, Woodgett JR (1991) Phosphorylation of c-Jun mediated by MAP kinase. Nature 353:670-674.

Qiu M-S, Green SH (1992) PC12 cell neuronal differentiation is associated with prolonged p21 ras activity and consequent prolonged ERK activity. Neuron 9:705-717.

Qu Z, Wolfram LA, Svaren J, Ehrengruber MU, Davidson N, Milbrandt J (1998) The transcriptional corepressor NAB2 inhibits NGF-induced differentiation of PC12 cells. J Cell Biol 142:1075-1082.

Segal RA, Greenberg ME (1996) Intracellular signaling pathways activated by neurotrophic factors. Annu Rev Neurosci 19:463-489. 
Shaywitz AJ, Greenberg ME (1999) CREB: a stimulus-induced transcription factor activated by a diverse array of extracellular signals. Annu Rev Biochem 68:821-861.

Smeal T, Binetruy B, Mercola DA, Birrer M, Karin M (1991) Oncogenic and transcriptional cooperation with Ha-ras requires phosphorylation of c-Jun on serines 63 and 73. Mol Cell Biol 12:3507-3513.

Srivastava S, Weitzmann MN, Kimble RB, Rizzo M, Zahner M, Milbrandt J, Ross FP, Pacifici R (1998) Estrogen blocks M-CSF gene expression and osteoclast formation by regulating phosphorylation of Egr-1 and its interaction with Sp-1. J Clin Invest 102:1850-1859.

Sukhatme VP, Cao X, Chang LC, Tsai-Morris C, Stamenkovitch D, Ferreira PCP, Cohen DR, Edwards SA, Shows TB, Curran T, LeBeau MM, Adamson ED (1988) A zinc-finger gene coregulated with c-fos during growth and differentiation, and after cellular depolarization. Cell 53:37-43.

Swirnoff AH, Milbrandt J (1995) DNA-binding specificity of NGFI-A and related zinc finger transcription factors. Mol Cell Biol 15:2275-2287.

Topilko P, Schneider-Maunoury S, Levi G, Baron-Van Evercooren A, Chennoufi AB, Seitanidou T, Babinet C, Charnay P (1994) Krox-20 controls myelination in the peripheral nervous system. Nature 371:796-799.
Tourtellotte WG, Milbrandt J (1998) Sensory ataxia and muscle spindle agenesis in mice lacking the transcription factor Egr3. Nat Genet 20:87-91.

Treisman R (1996) Regulation of transcription by MAP kinase cascades. Curr Opin Cell Biol 8:205-215.

Van Dam H, Wilhelm D, Herr I, Steffen A, Herrlich P, Angel P (1995) ATF-2 is preferentially activated by stress-activated protein kinase to mediate c-jun induction in response to genotoxic agents. EMBO J 14:1798-1811.

Watson A, Eilers A, Lallemand D, Kyriakis J, Rubin LL, Ham J (1998) Phosphorylation of c-Jun is necessary for apoptosis induced by survival signal withdrawal in cerebellar granule neurons. J Neurosci 18:751-762.

Wei F, Xu ZC, Qu Z, Milbrandt J, Zhuo M (2000) Role of EGR1 in hippocampal synaptic enhancement induced by tetanic stimulation and amputation. J Cell Biol 149:1325-1333.

Yamada M, Ikeuchi T, Aimoto S, Hatanaka H (1996) PC12h-R cell, a subclone of PC12 cells, shows EGF-induced neuronal differentiation and sustained signaling. J Neurosci Res 43:355-364.

Yamagishi S, Yamada M, Ishikawa Y, Matsumoto T, Ikeuchi T, Hatanaka H (2001) p38 mitogen-activated protein kinase regulates low potassium-induced c-Jun phosphorylation and apoptosis in cultured cerebellar granule neurons. J Biol Chem 276:5129-5133. 